\title{
Phytase activity in the human and rat small intestine
}

\author{
T H Iqbal, K O Lewis, B T Cooper
}

\begin{abstract}
Phytate is the major storage form of phosphorus in seeds and so is a common dietary constituent. Excessive ingestion of undegraded phytates can cause mineral deficiencies in humans. In addition, phytic acid is antineoplastic in animal models of both colon and breast carcinoma. There have been no previous studies quantifying phytase activity in the human small intestine although it is present in animals. Small intestinal phytase and alkaline phosphatase activity and distribution was measured in vitro in mucosal homogenates from two human small intestinal specimens obtained from transplant donors. Rat intestine was also studied for comparison. Phytase activity was found in human small intestine at low values (30 times less than that in rat tissue and 1000-fold lower than alkaline phosphatase in the same tissue). The activity was greatest in the duodenum and lowest in the ileum. In conclusion, the normal human small intestine has very limited ability to digest undegraded phytates. Although this may have adverse nutritional consequences with respect to metabolic cation imbalances, the presence of undigested phytate in the colon may protect against the development of colonic carcinoma.

(Gut 1994; 35: 1233-1236)
\end{abstract}

Phytate (myo-inositol hexaphosphate) is the major storage form of phosphorus in seeds and as such forms a variable large component of the diet of many animals and humans. ${ }^{1}$ Phytic acid is a strong chelator of cations and has been shown to cause deficiencies in minerals such as calcium, iron, zinc, and magnesium when present in excess in the human diet. ${ }^{2}$

Phytase (E.C.3.1.3.8.) is present in the small intestines of animals such as rats, calves, chickens, and pigs. ${ }^{3-5}$ Dietary phytate intake and the ability of the intestine to break down phytic acid have been extensively studied in animals because of the importance of phytic acid in mineral balance and the potentially deleterious effect of high concentrations of undigested phosphates in livestock excreta. ${ }^{67}$

Despite the fact that humans consume large amounts of phytates, which can cause mineral deficiencies, ${ }^{8}$ published works on the ability of the human intestine to degrade phytic acid are surprisingly sparse. There has only been one previous study on phytase activity in the human small intestine, which found it to be present but made no mention of the activity of the enzyme or its distribution in the intestine. ${ }^{5}$ Metabolic balance studies in human volunteers have suggested that the human intestine is poor at metabolising phytic acid. ${ }^{9}$

Our aim was to measure human intestinal phytase activity in vitro on fresh small intestinal material and to compare this with the activity in the rat. As there has been controversy in the past as to whether phytase activity actually results from alkaline phosphatase, ${ }^{10}$ we planned to measure alkaline phosphatase activity in the same tissues and to use phenyalalanine, which is known to inhibit alkaline phosphatase but not phytase. ${ }^{11}$

\section{Methods}

Phytase activity is determined by measuring the liberation of inorganic phosphate when inositol hexaphosphate is broken down. Most methods for measuring phosphate are based on the colour formed by the reduction of phosphomolybdate complexes. ${ }^{12}$ Various reducing agents have been used. The application of this principle to the determination of phytase activity has been complicated by the finding that phytate itself interferes in these colorimetric determinations of inorganic phosphate. ${ }^{13} \mathrm{~A}$ published method for the determination of phytase in duodenal biopsy specimens entails the reduction of phosphomolybdate complexes with ascorbic acid after the extraction of these complexes from remaining phytates using isobutyl/heptane. ${ }^{14}$

In a preliminary trial of this method, however, we found that the variability at the extraction and reduction phases made the procedure too imprecise for the determination of the very small amounts of phosphate released by the human tissue.

We therefore used a method for phosphate measurement using malachite green as the chromogen. ${ }^{15}$ This improved method does not entail phytate extraction before colour development. It also has the added advantage of not requiring protein precipitation as deproteination has been shown to release phosphate groups from cellular constituents. ${ }^{15}$

\section{REAGENTS}

The following reagents were used: sodium phytate $(30 \mathrm{mmol} / \mathrm{l})$, hydrochloric acid ( $5 \mathrm{~mol} / \mathrm{l})$; malachite green made up in acidified molybdate $(340 \mathrm{mg} / \mathrm{l})$; aqueous TWEEN solution (15 ml/l); ammonium molybdate in hydrochloric acid (34 mmol/1); aqueous urea solution $(360 \mathrm{~g} / \mathrm{l})$, aqueous zinc chloride (4 $\mathrm{mmol} / \mathrm{l}$ ); aqueous magnesium chloride $(40 \mathrm{mmol} / \mathrm{l})$. 


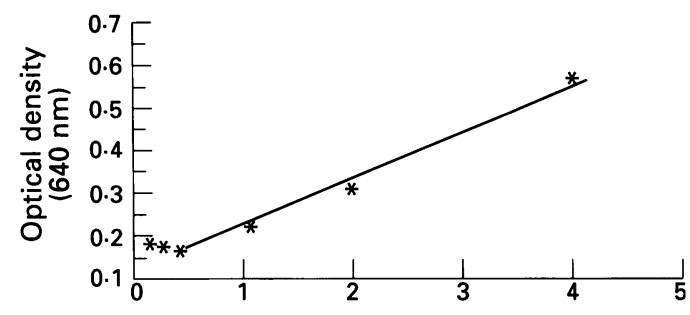

Phosphate concentration ( $\mathrm{mmol} / \mathrm{l})$

Figure 1: Working range for malachite green method.

\section{SPECIMENS}

Complete human small intestinal specimens were obtained from two previously fit subjects during organ harvesting for transplantation purposes. One was a 50 year old woman who died suddenly from a subarachnoid haemorrhage; the other a 40 year old man who died suddenly in a road traffic accident.

Rat small intestine was harvested from two Wistar male rats killed by cervical dislocation.

All tissue samples were immediately frozen in liquid nitrogen. Subsequently the rat and human donor specimens were kept at $-70^{\circ} \mathrm{C}$.

\section{PHYTASE DETERMINATION}

For the determination of phytase activity the brush borders were scraped off underlying tissue with a glass microscope slide before homogenisation.

The tissue (approx $200 \mathrm{mg}$ wet weight) was homogenised in $45 \mathrm{ml}$ cold $50 \mathrm{mmol}$ sucrose plus $2 \mathrm{mmol}$ TRIS $\mathrm{HCl}$ buffer ( $\mathrm{pH} 7 \cdot 1$ ) with 20 strokes of a Griffiths tube homogeniser. The homogenate was centrifuged at $6000 \mathrm{rpm}$ for three minutes and the supernatant separated from the pellet, which was discarded. An aliquot was taken for alkaline phosphatase activity, which was estimated on the 'Cobas-Bio' automated enzyme analyser using paranitrophenol phosphate as substrate, ${ }^{16}$ and for protein determination by the method of Bradford. ${ }^{17}$

Homogenate $(2 \mathrm{ml})$ was combined with $\mathrm{MgCl}_{2}$ solution $(100 \mu \mathrm{l})$ and zinc chloride solution $(100 \mu \mathrm{l})$. Sodium phytate substrate $(100 \mu \mathrm{l})$ was then added to the tests and water added to the blanks. Reagent blanks consisting of buffer with or without phytate were included. The tubes were then incubated at $37^{\circ} \mathrm{C}$ for two hours after which an aliquot $(100-500 \mu \mathrm{l})$ was taken for determination of inorganic phosphate content. Urea solution $(1 \mathrm{ml})$ was added to this to prevent protein precipitation and then malachite green reagent (4 ml) containing acidified molybdate. After allowing 10 minutes for colour development, the samples were read at $640 \mathrm{~nm}$ on a Pye Unicam PU8610 UV/Visible spectrophotometer.

For the measurements on rat tissue we found that $100 \mu \mathrm{l}$ aliquots from the incubation mixture gave good colour formation. The much smaller phytase activity in the human intestine, however, required $500 \mu l$ of incubate

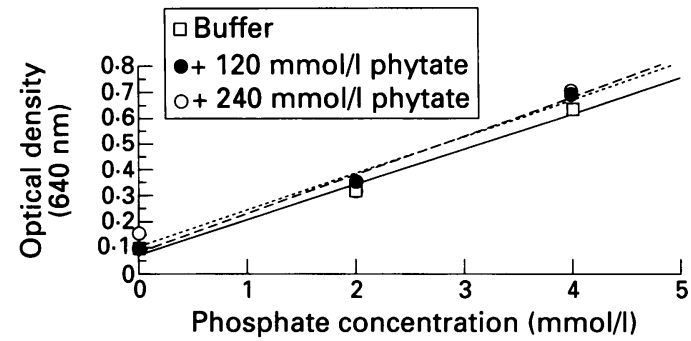

Figure 2: Effect of phytate on malachite green method for phosphate.

and at this concentration there is a contribution from undigested phytate to the final colour. This could be compensated for by reagent blanks consisting of buffer with and without phytate.

The concentrations of phosphate in the incubates and blanks were derived from the standard curve.

The phytase activity expressed as $\mu \mathrm{molP} / \mathrm{min} / \mathrm{mg}$ tissue was calculated as:

Phytase activity $(\mu \mathrm{molP} / \mathrm{mg}$ protein $/ \mathrm{min})=$
$(\mathrm{Tp}-\mathrm{T})-(\mathrm{Bp}-\mathrm{B}) /($ protein conc $\times$ time $)$

where Tp: tissue + phytate, T: tissue blank, Bp: buffer + phytate, B: reagent blank.

\section{Results}

WORKING RANGE OF MALACHITE GREEN METHOD

By plotting the absorbance of varying concentrations of phosphate standards (Fig 1) we derived a linear working range of between 1 and $5 \mathrm{mmol} / \mathrm{l}$.

FREEDOM FROM INTERFERENCE BY PHYTATE

Phosphate standards with added phytate up to 400 times that used in the final colour reaction product had negligible effect on the absorbance (Fig 2).

FREEDOM FROM SPONTANEOUS HYDROLYSIS OF PHYTATE

Reagent blanks comprising buffer with and without phytate showed negligible effects on the final absorbance from phytate showing that under the experimental conditions there was no spontaneous hydrolysis of phytic acid.

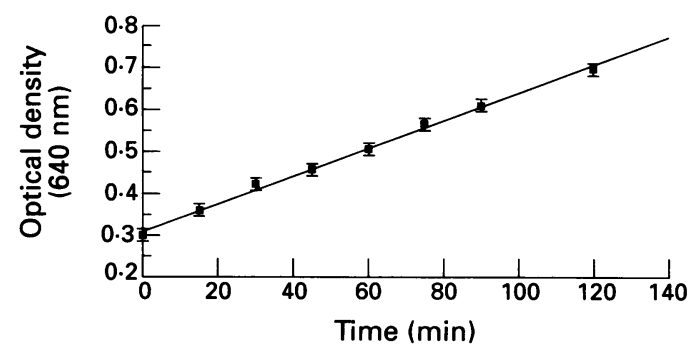

Figure 3: Rate of phosphate liberation during incubation of rat duodenal homogenate with phytate. 
TABLE I Rat duodenal phytase and alkaline phosphatase activity and kinetics. Mean (SD) on six replicates shown

\begin{tabular}{llll}
\hline & Activity & Vmax & Km (mmoll) \\
\hline Phytase (umolP/mg/min) & $270(4 \cdot 8) \times 10^{4}$ & 0.83 & $4 \cdot 21$ \\
Alkaline phosphatase (umolP/mg/min) & $2 \cdot 75(0 \cdot 02)$ & & \\
Alkaline phosphatase phytase ratio & 102 & & \\
\hline
\end{tabular}

TABLE II Human phytase and alkaline phosphatase. Mean (SD) on six replicates shown

\begin{tabular}{|c|c|c|c|}
\hline & $\begin{array}{l}\text { Phytase } \\
\text { (umolP/mg/min) }\end{array}$ & $\begin{array}{l}\text { Alkaline phosphatase } \\
\text { (umolP/mg/min) }\end{array}$ & $\begin{array}{l}\text { Ratio } \\
\text { (alkaline phosphatase/phytase) }\end{array}$ \\
\hline \multicolumn{4}{|l|}{ Duodenum: } \\
\hline Subject 1 & $9.33(0.8) \times 10^{-4}$ & $0.966(0.07)$ & 1083 \\
\hline Subject 2 & $6.50(0.19) \times 10^{-4}$ & $0.203(0.01)$ & 363 \\
\hline \multicolumn{4}{|l|}{ Jejunum: } \\
\hline Subject 1 & $3.67(0.5) \times 10^{-4}$ & $0.614(0.02)$ & 1702 \\
\hline Subject 2 & $4.50(0.12) \times 10^{4}$ & $0.647(0.01)$ & 1526 \\
\hline \multicolumn{4}{|l|}{ Ileum: } \\
\hline Subject 1 & $3.83(0.4) \times 10^{-4}$ & $1 \cdot 11(0.02)$ & 2938 \\
\hline Subject 2 & $3.00(0.6) \times 10^{-4}$ & $1.75(0.01)$ & 6089 \\
\hline
\end{tabular}

RECOVERY EXPERIMENT

Known concentrations of phosphate standards (1-6 $\mathrm{mmol} / \mathrm{l})$ were added to rat tissue homogenates in the absence of phytate substrate. Recoveries ranged from $90 \%$ at a concentration of $1 \mathrm{mmol} / \mathrm{l}$ to $83 \%$ at $6 \mathrm{mmol} / \mathrm{l}$

\section{RAT DUODENUM}

Linearity of reaction with time

Rat homogenate $(2 \mathrm{ml})$ was incubated with phytic acid for two hours and $100 \mu \mathrm{l}$ samples were taken every 15 minutes for immediately assay of phosphate content. Figure 3 shows the rate of phosphate production obeys first order kinetics.

Phytase activity, $\mathrm{Km}$, and Vmax for rat duodenum

Table 1 shows the results of phytase activity, alkaline phosphatase activity, and kinetics for phytase. The results are in good agreement with those found by other workers. ${ }^{11}$

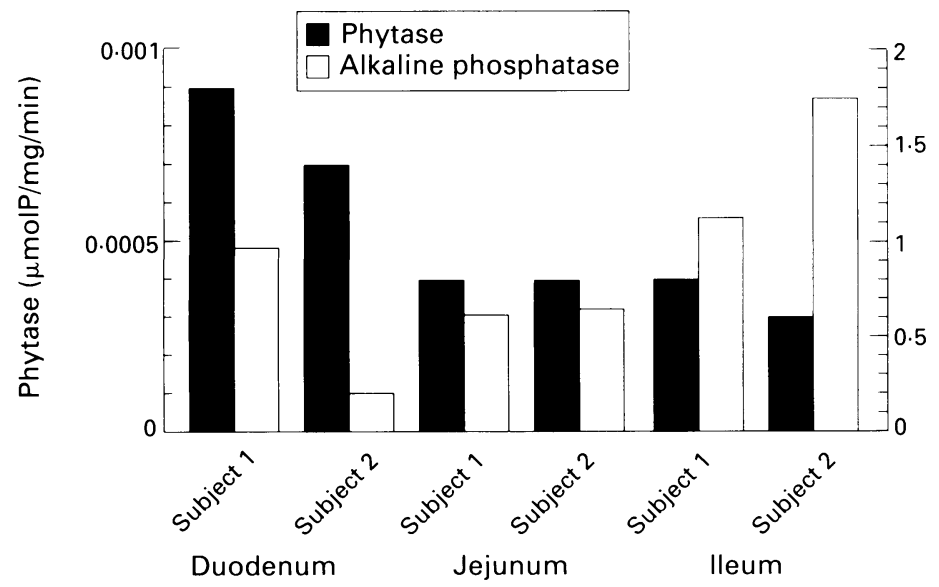

Figure 4: Distribution of human intestinal phytase and alkaline phosphatase in two subjects.

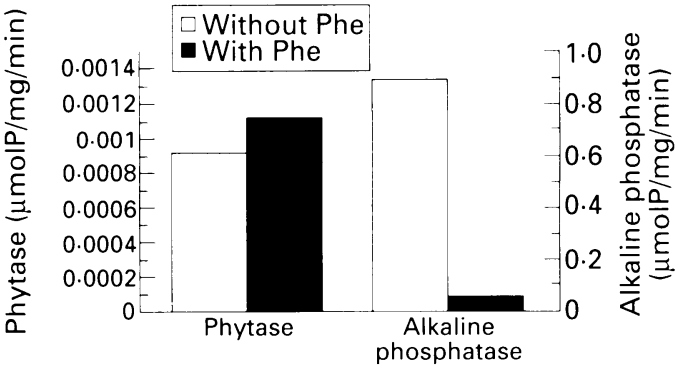

Figure 5: Effect of phenvlalanine (Phe) on human enzymes. Bars represent means of three replicates.

\section{HUMAN INTESTINE}

Human intestinal phytase activity

Table II shows the activity of phytase and alkaline phosphatase at different sites of the human small intestine.

It can be seen that there is much less phytase activity in the human small intestine compared with the rat and that this activity diminishes lower down the intestine.

Figure 4 shows the distribution of phytase and alkaline phosphatase activities in the two human intestines investigated. Determination of the kinetics of human phytase was beyond the sensitivity of the method because of the low phytase activity found in the human tissue.

\section{Phenylalanine inhibition}

We estimated phytase activity in three human duodenal homogenate replicates with and without the addition of phenylalanine (50 $\mathrm{mmol} / \mathrm{l})$. Alkaline phosphatase was estimated on the same homogenate with and without the addition of phenylalanine in the same concentration. Figure 5 shows that while the alkaline phosphatase activity was reduced by $95 \%$ by phenylalanine, there was no effect on the phytase activity.

\section{Discussion}

This is the first investigation to quantify the activity of human small intestinal phytase. In our study the proximal human small intestine was found to contain phytase activity at very low values, which declined distally along the intestine. Human duodenal phytase activity was roughly 1000 times lower than that of alkaline phosphatase and 30 times less than that seen in the rat duodenum. This measured activity did not result from alkaline phosphatase as shown by the lack of inhibition of phytase activity under conditions where alkaline phosphatase is almost completely inhibited. Other workers have found that phytate itself inhibits alkaline phosphatase. ${ }^{18} 19$ We found phytase activity in the rat small intestine comparable with that found by other workers using methods requiring phytate extraction. ${ }^{11}$ The only previous study on human phytase activity showed the enzyme in the human small intestine but did not report the levels of activity. ${ }^{5}$ The authors implied that they saw activity similar to that seen in the rat. 
This is at variance with the much lower activity found in this study.

Nutritionists have estimated human phytase activity indirectly by studying the breakdown of various foodstuffs by the whole gut in normal controls and in patients with ileostomies and have suggested that intestinal phytase activity is very low. ${ }^{920}$ Our direct measurements of human intestinal phytase activity in vitro would support these findings.

The ability of the small intestine to degrade phytic acid is of considerable nutritional importance as evidenced by the mineral deficiencies seen in human populations consuming large quantities of undegraded phytates. ${ }^{20-23}$ Phytates in the diet are probably hydrolysed mainly by endogenous phytase in food (for example, yeast phytase) and this breakdown probably occurs largely in the acid environment of the stomach. ${ }^{9}$ This would explain why most people taking diets containing modest amounts of phytates do not become deficient in minerals.

An additional recent development in phytate metabolism has been the hypothesis that phytate may be protective against colonic carcinogenesis. ${ }^{24}$ Phytic acid has recently been found to be anti-neoplastic in both mammary and colon carcinogenesis models in vivo in the rat. ${ }^{2526}$

The low level of phytase activity in the intestine dictates that, from the nutritional point of view, foodstuffs comprising high concentrations of phytic acid should undergo processing before human consumption. ${ }^{27}$ In view of the recent evidence, however, that phytic acid is anti-neoplastic ${ }^{26}$ it may be that consumption of undegraded phytates should be encouraged notwithstanding the nutritional implications.

1 Maga JA. Phytate; its chemistry, occurrence, food interactions, nutritional significance and methods of analysis. tions, nutritional significance and

2 Torre M, Rodriguez AR, Saura-Calixto F. Effects of dietary fiber and phytic acid on mineral availability. Crit Rev Foo Sci Nutr 1991; 1: 1-22.

3 Patwardhan VN. The occurrence of a phytin-splitting enzyme in the intestines of the albino rat. Biochem $\mathcal{F} 1937$ 31: 560-3.

4 Davies MI, Ritcey GM, Motzok I. Intestinal phytase and alkaline phosphatase of chicks: influence of dietary calcium, inorganic and phytic phosphorus and vitamin D3. Poult Sci 1970; 49: 1280-6.
5 Bitar K, Reinhold JG. Phytase and alkaline phosphatase ctivities in intestinal mucosa of rat, chicken, calf and man. Biochim Biophys Acta 1972; 268: 442-52.

6 Pointillart A, Fourdin A, Fontaine N. Importance of cereal phytase activity for phytate phosphorus utilization by rowing pigs fed diets containing triticale or corn. $f$ Nutr 1987; 117: 907-13.

7 Simons PCM, Versteegh HAJ, Jongbloed AW, Kemme PA Slump $\mathrm{P}$, Bos $\mathrm{KD}$, et al. Improvement of phosphorus availability by microbial phytase in broilers and pigs. $\mathrm{Br} \mathscr{f}$ Nutr 1990; 64: 525-40.

8 Erdman JW. Oilseed phytate. Nutritional implications. f Am Oil Chem Soc 1979; 56: 736-41.

9 Sandberg AS, Andersson H. Effect of dietary phytase on the digestion of phytate in the stomach and small intestine of humans. f Nutr 1988; 118: 469-73.

10 Davies NT, Flett AA. The similarity between alkaline phosphatase and phytase activities in rat intestine and their importance in phytate-induced zinc deficiency. Brf Nutr 1978; 39: 307-16.

11 Rao RK, Ramakrishnan CV. Studies on inositolphosphatase in rat small intestine. Enzyme 1985; 33: 205-15.

12 Varley $\mathrm{H}$. Gowenlock AH, Bell $\mathrm{M}$, eds. Practical clinical biochemistry. 5th ed. Vol 1. London: William Heinemann, 1980: 883-5.

13 Irving GCJ, Cosgrove DJ. Interference by myo-inositol hexaphosphate in inorganic orthophosphate determinations. Anal Biochem 1970; 36: 381-8.

14 Cooper JR, Gowing HS. A method for estimating phosphate in the presence of phytate and its application to the determination of phytase. Anal Biochem 1983; 132: 285-7.

15 Hohenwallner W, Wimmer E. The malachite green micromethod for the determination of inorganic phosphate. Clin Chim Acta 1973; 45: 169-75.

16 Hausamen TU, Helger R, Rick W, Gross W. Optimal conditions for the determination of serum alkaline conditions for the determination of serum alkaline 1967; 15: 241-5.

17 Bradford MM. A rapid and sensitive method for the quantitation of microgram quantities of protein utilizing the principle of protein-dye binding. Anal Biochem 1976; 72: 248-51.

18 Martin CJ, Evans WJ. Inactivation of intestinal alkaline phosphatase by inositol hexaphosphate-Cu(II) coordinate complexes. F Inorg Biochem 1991; 42: 161-75.

19 Martin CJ, Evans WJ. Reversible inhibition of intestinal alkaline phosphatase by inositol hexaphosphate and its $\mathrm{Cu}(\mathrm{II})$ coordinate complexes. F Inorg Biochem 1991; 42: Cu(II) coor

20 McCance RA, Widdowson EM Phyates in human nutrition. F Biochem 1935; 29B: 2694-9.

21 Hussain R, Patwardhan VN. Influence of phytate on the absorption of iron. Ind $\mathcal{F}$ Med Res 1959; 47: 676-82.

22 Berlyne GM, Ben-Ari J, Nord E, Shainkin R. Bedouin osteomalacia due to calcium deprivation caused by high phytic acid content of unleavened bread. Am $\mathcal{F}$ Clin Nutr 1973; 26: 910-11

23 Reinhold JG, Faradji B, Abadi P, Ismail-Beigi F. Decreased absorption of calcium, magnesium, zinc and phosphorus due to increase wheat bread. ₹ Nutr 1976; 106: 493-503.

24 Graf E, Eaton JW. Dietary suppression of colonic cancer. Fiber or phytate? Cancer 1985; 56: 717-8.

25 Jariwalla RJ, Sabin R, Lawson S, Bloch DA, Prender M Andrews V, et al. Effects of dietary phytic acid (phytate) on the incidence and growth rate of tumors promoted in Fisher rats by a magnesium supplement. Nutr Res $1988 ; 8$ : 813-27.

26 Wattenberg L, Lipkin M, Boone CW, Kellof G, eds. Cancer chemoprevention. Boca Raton, FL: CRC Press, 1992: 285-308.

27 Sandberg AS. The effect of food processing on phytate hydrolysis and availability of iron and zinc. Adv $\operatorname{Exp} M e d$ Biol 1991; 289: 499-508. 